\title{
Human serum inhibits adhesion and biofilm formation in Candida albicans
}

\author{
Xiurong Ding ${ }^{1}$, Zhizhong $\mathrm{Liu}^{2}$, Jianrong Su ${ }^{1 *}$ and Donghui Yan ${ }^{1}$
}

\begin{abstract}
Background: Candida albicans can form biofilms on intravenous catheters; this process plays a key role in the pathogenesis of catheter infections. This study evaluated the effect of human serum (HS) on C. albicans biofilm formation and the expression of adhesion-related genes in vitro. A C. albicans laboratory strain (ATCC90028) and three clinical strains were grown for $24 \mathrm{~h}$ in RPMI 1640 supplemented with HS or RPMI 1640 alone (as a control). The growth of biofilm cells of four strains was monitored by a Live Cell Movie Analyzer, and by XTT reduction assay. The expression of the adhesion-related genes BCR1, ALS1, ALS3, HWP1 and ECE1 was analyzed by RT-PCR at three time points (60 min, $90 \mathrm{~min}$, and $24 \mathrm{~h}$ ).

Results: In the adhesion phase, C. albicans cells kept a Brownian movement in RPMI medium containing HS until a large number of germ tubes were formed. In the control group, C. albicans cells quickly adhered to the bottom of the reaction plate. Compared with RPMI 1640, medium supplemented with 3-50\% HS caused a significant decrease in biofilm development (all $p<0.001$ ). However, the presence of HS had no significant inhibitory effect on the pre-adhered biofilms (all $p>0.05$ ). Biofilm formation was also inhibited by heat-inactivated and proteinase K pre-treated HS. The presence of $50 \% \mathrm{HS}$ did not significantly affect the planktonic growth of $C$. albicans ( $p>0.05)$. At three time points, HS inhibited expression of the ALS1 and ALS3 genes and promoted expression of the HWP1 and ECE1 genes. Significant up-regulation of BCR1 was observed only at the 90-min point.

Conclusions: Human serum reduces biofilm formation by inhibiting the adhesion of $C$. albicans cells. This response may be associated with the down-regulation of adhesion-related genes ALS1, ALS3 and BCR1. The inhibitory serum component is protease-resistant and heat stable.
\end{abstract}

Keywords: Human serum, Biofilm, Adhesion, Candida albicans

\section{Background}

Candida spp. are the fourth most common cause of nosocomial bloodstream infections [1], and Candida albicans accounts for approximately $50 \%$ of cases of candidemia [2]. Frequently, candidemia is associated with C. albicans colonization of indwelling devices, such as catheters, endotracheal tubes, and pacemakers [3-6]. In fact, C. albicans is the most common fungus in biofilms formed on medical devices [7]. Biofilm formation is a complex, multicellular process, consisting of cell adhesion, growth, morphogenic switching between yeast and filamentous states, and quorum sensing [8,9]. Adhesion of $C$. albicans cells to materials or host cells is a prerequisite

\footnotetext{
*Correspondence: sujianrongyy@126.com

${ }^{1}$ Clinical Laboratory Center, Beijing Friendship Hospital, Capital Medical University, Beijing 100050, China

Full list of author information is available at the end of the article
}

for biofilm formation, and cell-cell interactions may be important in the hierarchical organization of cells within the biofilm [6]. Moreover, biofilm formation of C. albicans is governed by a tightly woven gene network composed of six transcription regulators and their target genes [10]. The zinc finger transcription factor $B C R 1$ and its target genes, ALS1, ALS3, HWP1, and ECE1, play an important role, especially in the process of adhesion [11-13].

Human serum (HS) is a complex medium composed of proteins, lipids, and small molecules. The interaction of C. albicans with serum has been of long-standing interest in the field of fungal pathogenesis. Because Candida spp. can form biofilms on intravenous catheters and other inserted medical devices that may come into contact with blood, serum is regarded as an external cue to trigger biofilm formation. Yuthika et al. [14] reported that 3\% human serum can promote the formation of C. albicans 
biofilms. However, other researches revealed that serum can inhibit biofilm formation in some bacteria. Another study showed that human serum and fetal bovine serum (FBS) inhibit biofilm formation in Staphylococcus aureus [15], and Hammond et al. [16] found that adult bovine serum (ABS) or adult human serum (AHS) also inhibits $P$. aeruginosa biofilm formation on plastic surfaces, including intravenous catheters. Some studies revealed the ability of serum components to prevent the formation of bacterial biofilms. It was reported that bovine serum albumin (BSA) caused a significant decrease in biofilm development [16]. Abraham et al. indicated that a low molecular weight component of human serum inhibits biofilm formation in Staphylococcus aureus [15]. In addition, one component of innate immunity also prevents bacterial biofilm development [17].

Therefore, our hypothesis is that the positive effect of human serum on Candida albicans biofilm formation may be due to many factors, so it is necessary to study the related molecular mechanism.

\section{Results}

\section{The C. albicans adhesion process}

To directly observe the adhesion process of C. albicans, the Live Cell Movie Analyzer was used. For the first 2 or $3 \mathrm{~h}$ of biofilm formation, we took photos once per minute by means of continuous photographic techniques. When those pictures were played back in rapid succession, we got dynamic images of biofilm growth. Movie 1 shows that cells of $C$. albicans quickly adhered to the surface of polypropylene microtiter plates, formed germ tubes, and gradually extended in RPMI 1640 without HS (Additional file 1: Movie 1). However, in the RPMI 1640 with 50\% HS, the cells of the same strain kept a Brownian motion at the beginning and could not quickly clung to the bottom of the plate. The Brownian motion lasted as long as about $2 \mathrm{~h}$. The motion did not stop until the formation of a large number of germ tubes (Additional file 1: Movie 2). In the next hour (120-180 min), almost no C. albicans cells kept a Brownian motion, but the hyphae grew longer (Additional file 1: Movie 3). Movie 3 further shows that Brownian motion stops after $2 \mathrm{~h}$ (Additional file 1: Movie 1, Movie 2, and Movie 3).

\section{Effect of human serum on germ tube formation of C. albicans}

C. albicans cells were cultured in RPMI 1640 with and without $50 \% \mathrm{HS}$, and germ tube formation was continuously observed at $30,60,90,120$, and 180-min time points by Live Cell Movie Analyzer. For the first $90 \mathrm{~min}$ of culture, the germ tube formation rate of $C$. albicans cells in the experimental group (RPMI 1640 containing 50\% human serum) was significantly lower than that in the control group. Over $2 \mathrm{~h}$ of incubation, there was no significant difference in the rate of germ tube formation between the two groups. With the further extension of incubation time (from $2 \mathrm{~h}$ to $3 \mathrm{~h}$ ), the amount of hyphae gradually increased in the experimental group, just as in the control group (Additional file 2).

\section{Effect of human serum on C. albicans biofilms}

Data comparing biofilm growth of $C$. albicans strains in the absence or presence of different concentrations of $\mathrm{HS}$ were obtained using a XTT reduction assay. Initially, the tests were performed using cells of strain ATCC90028 in RPMI 1640 containing different concentrations of HS ( $3 \%, 5 \%, 10 \%$, and $50 \%)$.

It was found that HS inhibited the biofilm formation of C. albicans in a dose-dependent manner (from 3\% to $50 \%$ ). More specifically, $3 \%$ HS was sufficient to inhibit biofilm formation $(p<0.001)$, and this anti-biofilm effect increased with increasing HS concentrations (Figure 1A). However, HS had no significant inhibitory effect on pre-adhered C. albicans biofilms in vitro (all $p>0.05$ ), even when the concentrations were as high as 50\% (Figure 1B).

To confirm the hypothesis that this effect was not specific to strain ATCC90028, we tested three unrelated clinical strains and found that HS also had the same effect on all three clinical strains (data not shown).

\section{Characterization of the inhibitory components}

To further investigate the component(s) of serum that affect the adhesion of $C$. albicans, we heated the serum at $56^{\circ} \mathrm{C}$ for $30 \mathrm{~min}$. This heat treatment did not abrogate the inhibitory activity. Heat-inactivated serum still inhibited biofilms in a dose-dependent manner (Figure 2A). At a concentration of $3 \%$, heat-inactivated HS significantly inhibited biofilm formation $(p<0.001)$, and with increasing HS concentrations, the effect of HS on biofilm formation became more pronounced. To eliminate the possibility that a heat stable protein was responsible for the biofilm inhibition, proteinase $\mathrm{K}$ was used to degrade proteins in the HS, but this also did not affect the ability of serum to inhibit biofilm formation (Figure 2B). Biofilm formation was significantly reduced in proteinase K-treated serum compared with the control group (all $p<0.001$ ). At a concentration of $3 \%$, proteinase K-treated HS significantly inhibited biofilm formation $(p<0.001)$, and with increasing HS concentrations, the effect of HS on biofilm formation became more pronounced. The results were similar in all four C. albicans strains (data not shown).

\section{Effect of human serum on planktonic growth of $C$. albicans}

To confirm that inhibition of biofilm formation was not due solely to growth inhibition, the effect of HS on the planktonic growth of $C$. albicans was investigated. Timegrowth curves indicated that the presence of $50 \% \mathrm{HS}$ (fresh HS, heat-inactivated HS, or proteinase K-treated 

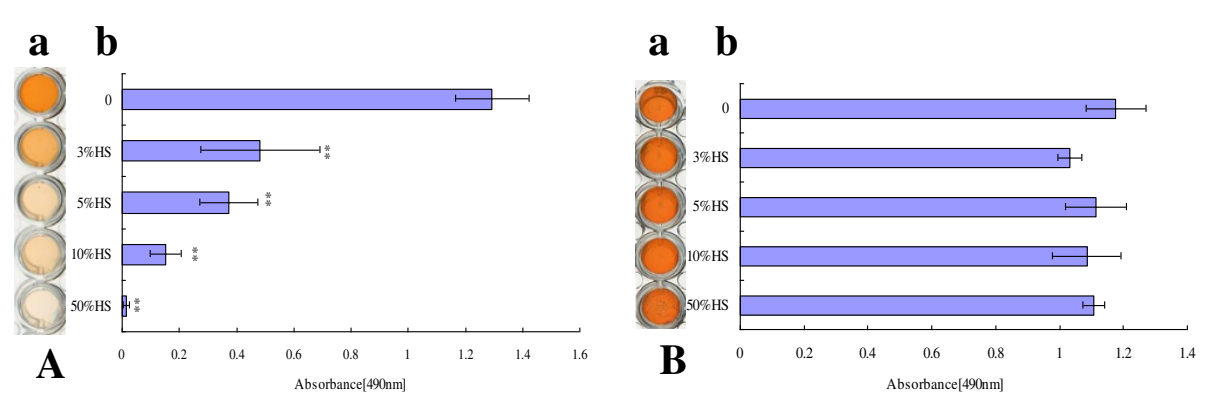

Figure 1 Effect of human serum on C. albicans biofilms. A) Analysis of biofilm formation in the presence of normal human serum (HS). ATCC90028 was grown in polypropylene microtiter plates at $37^{\circ} \mathrm{C}$ for $24 \mathrm{~h}$ in the presence of different concentrations of HS. a. Scanned image of the XTT reduction assay for quantitation of biofilms. $\mathbf{b}$. Quantitation of biofilms by XTT reduction assay. B) Different concentrations of HS were added to pre-adhered biofilms of ATCC90028 and incubated in RPMI 1640 medium for an additional $24 \mathrm{~h}$ at $37^{\circ} \mathrm{C}$. a. Scanned image of the XTT reduction assay for quantitation of biofilms. $\mathbf{b}$. Quantitation of biofilms by XTT reduction assay. All experiments were done in triplicate with three technical repeats on separate days with similar results and shown as a representative image. RPMl 1640/HS vs. RPMI $1640,{ }^{* *} p<0.01$.

HS) did not significantly affect the growth of C. albicans (all $p>0.05$ ) (Figure 3). To confirm the hypothesis that this effect was not specific to strain ATCC90028, we tested three unrelated clinical strains and found that HS had the same effect on all three clinical strains as well (data not shown).

\section{Effect of human serum on expression of adhesion-related genes}

To elucidate the potential molecular mechanism behind the ability of HS to prevent growth of C. albicans biofilms, total RNA was isolated from biofilms of four C. albicans strains grown in RPMI 1640 medium with or without $50 \%$ HS at three time points $(60 \mathrm{~min}, 90 \mathrm{~min}$ and $24 \mathrm{~h}$ ). The expression levels of specific genes that were previously implicated in mediating the adhesion of $C$. albicans cells were determined by real-time RT-PCR. HS had varying effects on different genes in different tested strains (data not shown), but the general trend of these genes was consistent. HS down-regulated the expression of the adhesion-related genes ALS1 (1.1 to 3.0-fold) and ALS3 (1.5 to 3.8-fold), but up-regulated the expression of the hypha-related genes HWP1 (1.1 to 2.4-fold) and ECE1 (1.1 to 4.2 -fold) at all three time points (Figure 4). Particularly, expression levels of ALS1 (2.5 and 3.0-fold) and ALS3 (3.7 and 3.8-fold) showed significant differences at both $90 \mathrm{~min}$ and $24 \mathrm{~h}(p<0.05$ or $p<0.01)$ (Figure 4B,C). Only at the 90 -min time point were the transcription levels of HWP1 (2.4-fold) and ECE1 (4.2-fold) significantly higher $(p<0.05$ or $p<0.01)$ (Figure 4B). The transcription level of $B C R 1$ was significantly higher at $90 \mathrm{~min}$ (3.3-fold, $p<0.01$ ) (Figure 4B), but $B C R 1$ levels were significantly lower at both $60 \mathrm{~min}(2.8$-fold, $p<0.05)$ and $24 \mathrm{~h}$ (5.6-fold, $p<0.01$ ) (Figure 4A,C).

\section{Discussion}

To make the transition from a commensal organism to a systemic pathogen, $C$. albicans must first enter the bloodstream. It can do so by taking advantage of medical devices, such as intravenous catheters, to enter the bloodstream
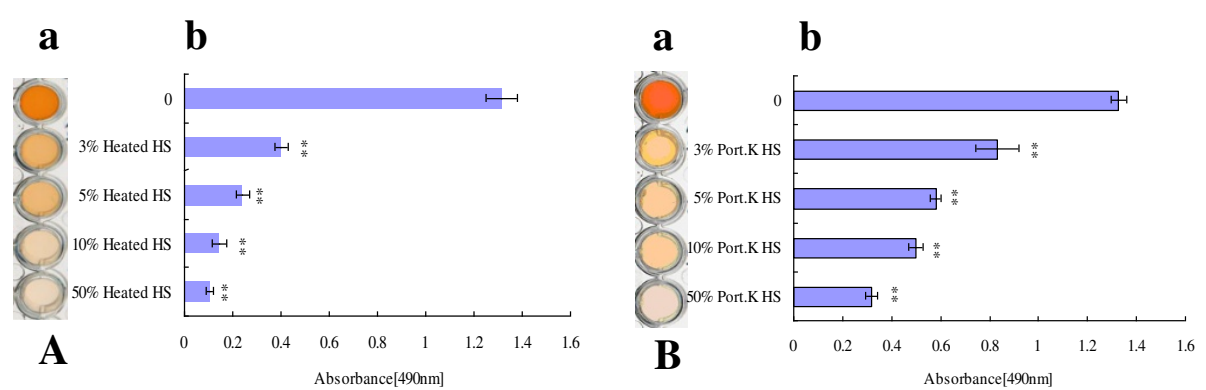

Figure 2 The component(s) of serum inhibit C. albicans biofilm formation. A) Biofilm formation of C. albicans ATCC90028 was examined in the presence of different concentrations of heat-inactivated human serum for $24 \mathrm{~h}$ at $37^{\circ} \mathrm{C}$. $\mathbf{a}$. Scanned image of the XTT reduction assay for quantitation of biofilms. b. Quantitation of biofilms by XTT reduction assay. B) Biofilm formation of C. albicans ATCC90028 was examined in the presence of different concentrations of proteinase K-treated human serum for $24 \mathrm{~h}$ at $37^{\circ} \mathrm{C}$. (a. Scanned image of the XTT reduction assay for quantitation of biofilms. $\mathbf{b}$. Quantitation of biofilms by XTT reduction assay.) All experiments were done in triplicate with three technical repeats on separate days with similar results. RPMI 1640/HS vs. RPMI 1640, ${ }^{* *} p<0.01$. 


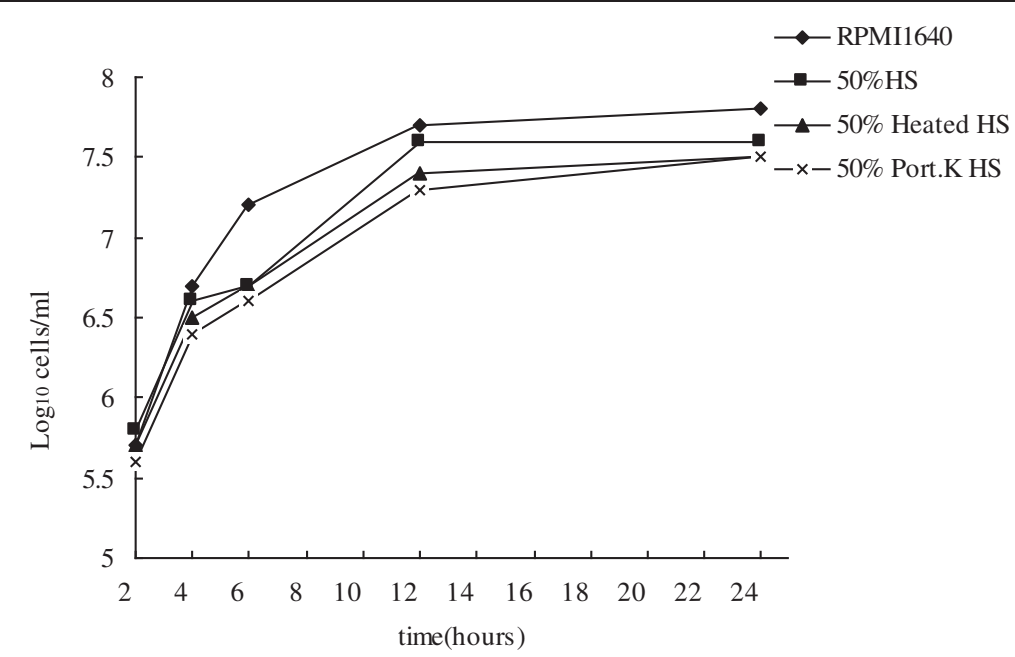

Figure 3 Effect of human serum on planktonic growth of C. albicans. Twenty-four-hour growth curves showing 50\% HS, 50\% heat-inactivated HS, and 50\% proteinase K-treated HS against C. albicans ATCC90028 in RPMI 1640. Symbols: $\bullet$, growth control; $\mathbf{a}, 50 \%$ HS; $\mathbf{\Delta}, 50 \%$ heated HS; $\times, 50 \%$ proteinase K-treated HS.

directly, or it can cross intact or damaged gastrointestinal mucosa and enter into the bloodstream [5,18]. In the bloodstream, C. albicans is exposed to the innate immune defenses. As a part of human innate immune system, serum and its components show different degrees of protection against systemic candidiasis.

In this study, the natural proliferation condition of $C$. albicans was monitored continuously by a Live Cell Movie
Analyzer. C. albicans cells in HS moved with Brownian motion in the initial stage of culture, then failed adhere to the surface of polystyrene plates. This indicates that $C$. albicans may remain in a suspended status at the early period of entering the blood stream. Previous studies showed that free-flowing $C$. albicans can be rapidly cleared from the blood [19]. We determined that human serum facilitates the removal of C. albicans by inhibiting
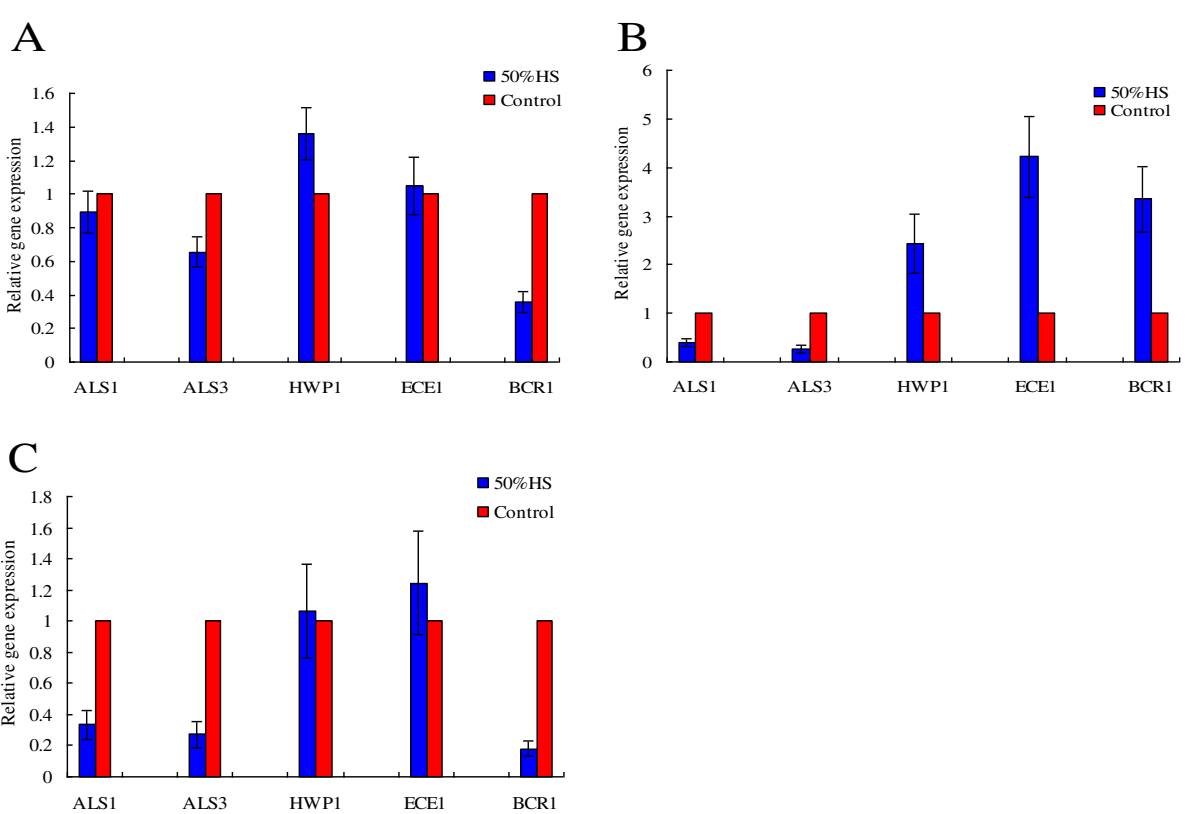

Figure 4 Expression of $\boldsymbol{C}$. albicans adhesion-related genes. Candida albicans cells were incubated in the absence or presence of HS (50\%) and the expression of target genes was determined by RT-PCR. Housekeeping gene ACT1 was used as an internal control. Each gene was assessed in triplicate, and the experiment itself was performed in biologic duplicate. The data shown here are a representative graph of strain ATCC90028. A) Expression of genes ALS1, ALS3, HWP1, ECE1, and BCR1 following the treatment with HS for $60 \mathrm{~min}$. B) Different expression of the target genes following treatment with HS for 90 min. C) Target gene expression level following treatment with HS for $24 \mathrm{~h}$. 
the adhesion of C. albicans on the surface of the endothelial cells. C. albicans possesses virulence factors that are needed to establish candidiasis that are involved in the many steps of this complicated process, such as adhesion, phenotypic switching, morphogenesis, and biofilm formation [20]. Some factors in the bloodstream, such as temperature and serum, facilitate the filamentation of C. albicans [21-23]. It is reported that filamentation is favorable for $C$. albicans adhesion and biofilm formation $[24,25]$. However, filamentation failed to offset the biofilm formation inhibition caused by the HS-induced adhesion defect, as demonstrated in our study.

We also investigated the effect of serum on germ tube formation in C. albicans. Our results showed that the rate of germ tube formation is high in HS medium, but compared with the control group, germ tube formation in the experimental group was delayed in the initial stage of culture (within $90 \mathrm{~min}$ ). This may be one of the reasons for HS-induced adhesion inhibition. Based on these results, we also think that RPMI 1640 medium may be a more suitable medium than human serum to conduct germ tube testing in C. albicans.

In the initial stage of biofilm culture (the adhesion period), low serum concentrations suppressed C. albicans biofilm formation. However, the serum had no effect on pre-adhered biofilms (90 min), even if the serum was in a very high concentration. Thus, we concluded that serum may inhibit biofilm formation by preventing the adhesion of C. albicans, in consensus with previous studies $[15,16]$. Recent studies showed that addition of as little as 3\% human serum to media can promote $C$. albicans biofilm formation [14], contrary to our results. This may be explained by the use of different materials, such as serum, culture medium, strains, adhesive medium, and so on.

It has been reported that IgG, LL-37, transferrin and lactoferrin, at concentrations close to those found in vivo, can reduce the capacity of $C$. albicans and bacteria to adhere to polystyrene $[17,26-28]$. Thus, we initially hypothesized that some protein or antimicrobial peptide in human serum may inhibit the adhesion of $C$. albicans, and as a consequence, reduce biofilm formation. However, our results suggest that the compound in serum that inhibits C. albicans biofilm formation is not proteinaceous. Abraham et al. [15] found that a low molecular weight component of human serum inhibits biofilm formation in Staphylococcus aureus, and the component was protease-resistant and heat stable. We conclude here that human serum may also contain non-protein component(s) that can inhibit the adhesion and biofilm formation of fungi and bacteria. To confirm this hypothesis, future studies are needed to identify this component of human serum.

In this study, planktonic growth of C. albicans was not inhibited by human serum, indicating that inhibition of biofilm formation was not due solely to growth inhibition.

Biofilm formation of C. albicans, a process that depends upon both cell-cell and cell-substrate adherence, is controlled by a tightly woven network of genes [10]. Among this gene network, $B C R 1$ is one of the best-characterized biofilm regulators [11-13,29]. Through its adhesin targets ALS1, ALS3, HWP1 and ECE1, BCR1 mediates cellsubstrate and cell-cell interactions in biofilms [30,31]. In this study, at the adhesion stage of biofilm formation (60 min, $90 \mathrm{~min}$ ), the expression of BCR1 went from less than to significantly higher than that of the control group. This may be due to the promoting effect of serum on hypha growth, as $B C R 1$ RNA accumulation depends on the hyphal developmental activator TEC1 [32]. ALS1 and $A L S 3$ are members of the agglutinin-like sequence $(A L S)$ gene family that encodes cell-wall glycoproteins [33]. Most Als proteins have adhesin functions [34,35]. Mutational analysis indicates that strains lacking all functional $A L S 1$ and $A L S 3$ alleles (als1 1 /als $1 \Delta$ als3 4 /als $3 \Delta$ ) failed to produce any detectable adherent cells in biofilm models both in vivo and in vitro [30], or in actual biofilm formation. The als1 1 /als $1 \Delta$ mutants produced substantial biofilms, but the biofilms often sloughed off the substrate, while the als $3 \Delta$ /als $3 \Delta$ mutant only produced scant, disorganized biofilms on catheter material in vitro [12]. Our data on transcript analysis showed that the expression of ALS1 and ALS3 were reduced at different time points in the biofilm adhesion stage. Therefore, we supposed that the anti-adhesion effect of human serum might occur via inhibition of the expression of $A L S 1$ and $A L S 3$, and therefore affect biofilm formation. Previous studies have shown that a $b c r 1 \Delta / b c r 1 \Delta$ mutant, which has reduced expression of $A L S 1, A L S 3$, and other adhesins, has defective biofilm formation in both an in vitro and in vivo catheter model [12]. In this study, at $90 \mathrm{~min}$ of growth, the change in the levels of BCR1 level was different from ALS1 and ALS3, indicating that $A L S 1$ and $A L S 3$ are also affected by other factors $[8,36]$.

Interestingly, human serum promotes the expression of HWP1 and ECE1. HWP1 is a well-characterized hyphaspecific gene that can mediate $C$. albicans cell-cell interactions and improve biofilm formation $[37,38]$. Nobile et al. [30] found that the expression of Hwp1 in Saccharomyces cerevisiae permits adherence to wild-type $C$. albicans but not an als $1 \Delta$ /als $1 \Delta$ als $3 \Delta$ /als3 $\Delta$ double mutant. In addition, a TDH3-HWP1 hybrid gene could not promote biofilm formation in the als1 1 /als $1 \Delta$ als $3 \Delta$ /als $3 \Delta$ background in vitro or in vivo. Our study revealed that human serum decreased the expression level of $A L S 1$ and $A L S 3$, so overexpression of $H W P 1$ failed to save the adhesion and biofilm formation of $C$. albicans. ECE1 was regarded as a hyphal-induced gene, although its mechanism of action is uncertain. Our study showed that hyphae were 
significantly greater in the presence of serum than in the control group, especially in the mature biofilm stage (data not shown). This may be due to the increase of ECE1 and HWP1 [23].

In this study, we also tested the expression of adhesion-related genes in biofilms grown for $24 \mathrm{~h}$ and found that the expression trend of related genes at this time was similar to the adhesion phase, both in the reduction of $A L S 1$ and $A L S 3$ and the up-regulation of $H W P 1$ and ECE1. The expression of the BCR1 gene, however, was significantly inhibited. Its level was far lower than that of the control group. All in all, the serum reduces $B C R 1$ gene expression, and that might be a reason for biofilm inhibition.

\section{Conclusion}

In summary, our study demonstrated that human serum may reduce the biofilm formation of $C$. albicans by inhibiting adhesion. This inhibition is partly due to the downregulation of adhesion-related genes, including ALS1, ALS3 and $B C R 1$. Meanwhile, the inhibitory effect of human serum is caused by non-protein components in the serum. Therefore, biofilm formation in vivo may be "selected for" (possibly by immune pressure and sheer forces) rather than "induced" by serum at the level of transcription.

\section{Methods}

\section{Ethics Statement}

This study was approved by the Medical Ethics Committee of Beijing Friendship Hospital, Capital Medical University, Beijing, China (approval \#BJFH-EC/2013-014), and individual informed consent was waived.

\section{Organisms}

Four Candida albicans strains (laboratory strain ATCC 90028 and three clinical isolates of C. albicans: 9079, y2991, 31448) were tested in this study. The three $C$. albicans bloodstream isolates were collected from three different intensive care patients admitted to the Beijing Friendship Hospital and were confirmed according to standard mycological methods, such as the germ tube test in serum, growth on CHROMagar Candida medium, and API testing methods. All isolates were stored in skim milk at $-80^{\circ} \mathrm{C}$ until use.

\section{Medium and growth conditions}

Prior to each experiment, $C$. albicans strains were subcultured on Sabouraud's Agar (SDA) at $35^{\circ} \mathrm{C}$ for $24 \mathrm{~h}$. To prepare the yeast inocula for biofilm growth, a loopful of the SDA culture was transferred into $25 \mathrm{ml}$ of liquid yeast extract-peptone-dextrose (YPD) medium (1\% yeast extract, $2 \%$ peptone, $2 \%$ glucose) and incubated at $30^{\circ} \mathrm{C}$ for $18 \mathrm{~h}$ in an orbital shaker (75 rpm). Then, the cells were harvested by centrifugation, washed twice in PBS
(pH 7.2), re-suspended in RPMI 1640 medium (buffered to a pH of 7.0 with $0.165 \mathrm{M}$ morpholinepropanesulfonic acid), and counted after serial dilution by a hemocytometer.

\section{Human serum}

Human serum (HS) was pooled from healthy blood donors, and heat-inactivated serum was prepared by heating at $56^{\circ} \mathrm{C}$ for $30 \mathrm{~min}$. Proteinase K-treated serum was prepared by incubating with $50 \mathrm{mg} / \mathrm{mL}$ proteinase $\mathrm{K}$ at $58^{\circ} \mathrm{C}$ for $1 \mathrm{~h}$ followed by incubation at $85^{\circ} \mathrm{C}$ for $1 \mathrm{~h}$ to inactivate the protease. All fractions were filter-sterilized $(0.22-\mathrm{mm}$ pore size filter).

\section{Biofilm formation}

Fungal biofilms were prepared as described on commercially available, pre-sterilized, flat-bottomed 96 -well polystyrene microtiter plates (Corning) [39]. Briefly, a cell suspension of $1.0 \times 10^{6}$ cells $/ \mathrm{ml}$ was prepared in RPMI 1640 and RPMI $1640+50 \%, 10 \%, 5 \%$ or $3 \%$ HS. From those suspensions, $100 \mu \mathrm{l}$ was introduced into wells and incubated at $37^{\circ} \mathrm{C}$ for $24 \mathrm{~h}$ without agitation, which allowed the cells to attach to the surface of the plate and form the biofilm structure.

To investigate the effect of HS on pre-adhered biofilms, C. albicans biofilms were prepared for $90 \mathrm{~min}$ (the adhesion phase) at $37^{\circ} \mathrm{C}$ as described above. The wells were washed twice with PBS to remove loosely adherent cells. Then, fresh RPMI $1640(100 \mu \mathrm{l})$, containing different concentrations $(3-50 \%)$ of HS were added and the plate was further incubated for $24 \mathrm{~h}$ at $37^{\circ} \mathrm{C}$. RPMI 1640 medium without HS was included in control wells. The metabolic activity of the C. albicans biofilms was determined quantitatively using XTT reduction assay.

\section{Dynamic monitoring of the adhesion process}

Standard cell suspension of C. albicans was prepared in RPMI1640 or RPMI1640 containing different concentrations ( $3 \%$ to $50 \%$ ) of $\mathrm{HS}$, and $100 \mu \mathrm{l}$ of those suspensions was introduced into 96-well polystyrene microtiter plates. After standing for $3 \mathrm{~min}$, the plates were placed on Live Cell Movie Analyzer (JuLI' Br., NanoEnTek Inc., Seoul, Korea) and incubated at $37^{\circ} \mathrm{C}$. The instrument was set to continuous photographing mode with exposure $5 \%$, brightness $13 \%$, zoom level 4, interval $1 \mathrm{~min}$, and total time $2 \mathrm{~h}$ (the experimental group was prolonged to $3 \mathrm{~h}$ ). When it was finished, a total of 121 or 181 photos were obtained for the control and experimental groups, respectively. Then, those pictures were played back in rapid succession to observe the dynamic changes of the fungal cells (playing at a speed of 10 frames/s).

\section{Quantitation of biofilms}

At the end of the incubation, the supernatant was aspirated and the wells washed twice with PBS. The quantitation of 
biofilms was determined using 2,3-bis (2-methoxy-4nitro-5-sulfo-phenyl)-2H-tetrazolium-5-carboxanilide (XTT) reduction assay that measures the activity of mitochondrial dehydrogenase [40]. XTT solution $(1 \mathrm{mg} / \mathrm{ml})$ was prepared by dissolving XTT powder (Sigma, Shanghai, China) in PBS, and the solution was filter-sterilized $(0.22$-mm pore size filter). XTT solution $(40 \mu \mathrm{l})$ was mixed with freshly prepared menadione solution $(0.4 \mathrm{mM} ; 2 \mu \mathrm{l})$ (Sigma, Shanghai, China) at 20:1 (v/v) immediately prior to the assay. Thereafter, PBS $(158 \mu \mathrm{l})$ was mixed with XTT-menadione solution $(42 \mu \mathrm{l})$, transferred to each well containing pre-washed biofilms, and incubated in the dark for $3 \mathrm{~h}$ at $37^{\circ} \mathrm{C}$. After the incubation, the colored supernatant $(100 \mu \mathrm{l})$ was transferred to new microtiter plates, and the optical density of the supernatant was measured at $490 \mathrm{~nm}$ with a microplate reader (BIORAD, CA, USA) and imaged by a flatbed scanner (EPSON PERFECTION V700 PHOTO, Beijing, China). All assays were carried out in at least three replicates on different days.

Effect of human serum on planktonic growth of $C$. albicans A cell suspension of $10^{5}$ cells $/ \mathrm{ml}$ was prepared in RPMI 1640, RPMI $1640+50 \%$ fresh HS, 50\% heat-inactivated HS and 50\% proteinase K-treated HS. At predetermined time points $(0,2,4,6,12$ and $24 \mathrm{~h}$ after incubation with agitation at $\left.30^{\circ} \mathrm{C}\right), 100 \mu \mathrm{l}$ aliquot was removed from every solution and serially diluted 10 -fold in sterile water. A $100 \mu \mathrm{l}$ aliquot from each dilution was streaked on the Sabouraud dextrose agar plate. Colony counts were determined after incubation at $30^{\circ} \mathrm{C}$ for $48 \mathrm{~h}$. Three independent experiments were performed. Effect of human serum on growth of C. albicans was determined by analyzing the time-growth curve.

\section{RT-PCR analysis of C. albicans adhesion-related genes}

Quantitative real-time reverse transcription PCR (RT-PCR) was used to compare mRNA abundances of the genes of interest. A standard cell suspension of C. albicans $(1 \mathrm{ml})$ was transferred into the wells of a pre-sterilized, flatbottomed 24-well polystyrene microtiter plate (Corning, NY, USA). After incubation for $60 \mathrm{~min}, 90 \mathrm{~min}$ or $24 \mathrm{~h}$ at $37^{\circ} \mathrm{C}$ with or without HS, the supernatant was aspirated and the wells were washed twice with PBS. Total RNA was extracted from C. albicans biofilms using FastPure ${ }^{\mathrm{Tm}}$ RNA kit (TaKaRa Biotechnology Co. Ltd, Dalian, China), according to the manufacturer's manual. RNA concentrations and RNA purity were determined using a BioPhotometer spectrophotometer (Eppendorf, Germany). An equal amount of RNA was subjected to cDNA synthesis using the PrimeScript RT reagent kit (TaKaRa Biotechnology Co. Ltd, Dalian, China).

Real-time PCR primers were designed for the target genes ALS1, ALS3, ECE1, HWP1, and BCR1 using Primer
Express 3.0 software (Applied Biosystems, CA, USA). The $\beta$-actin gene $(A C T 1)$ was used as an endogenous reference gene. The sequences of forward and reverse primers are shown in Table 1. Real-time RT-PCR was performed with a StepOnePlus ${ }^{\text {Ta }}$ real-time PCR system (Applied Biosystems, CA, USA), and SYBR Premix Ex Taq ${ }^{\text {Tnx }}$ II was used as a reagent specifically designed for intercalator-based real-time PCR using SYBR Green I. All PCR reaction mixtures contained: $10 \mu \mathrm{l} \mathrm{SYBR}{ }^{\circ}$ Premix Ex TaqTM II (2X), $2 \mu \mathrm{l}$ first strand cDNA, $0.5 \mu \mathrm{l}$ each primer, $0.4 \mu \mathrm{l}$ ROX Reference Dye (50X) and $\mathrm{dH}_{2} \mathrm{O}$ to the final volume of $20 \mu \mathrm{l}$. The program for amplification was $95^{\circ} \mathrm{C}$ for $30 \mathrm{~s}$ as an initial denaturation step, followed by 40 cycles of PCR consisting of $95^{\circ} \mathrm{C}$ for $5 \mathrm{~s}$ and $60^{\circ} \mathrm{C}$ for $30 \mathrm{~s}$. Negative controls (water as template) were included in each run. After amplification, a melting curve was analyzed to confirm the specificity of the primers. Expression of each investigated gene was normalized to the housekeeping $A C T 1$ gene and analyzed using comparative $C \mathrm{t}$ method $(\triangle \Delta C \mathrm{t})$. Expression of $A L S 1, A L S 3, E C E 1, H W P 1$, and $B C R 1$ genes from cells grown under serum-treatment condition was indicated as relative expression to that of genes from untreated yeast cells. Each experimental condition was performed in duplicate and each experiment was repeated twice on two different days for reproducibility.

\section{Statistical analysis}

Data were described as mean \pm SD. All statistical analyses were performed by statistical analysis computer software package SPSS 17.0 (SPSS Inc., IL, USA). Student's $t$-test or one-way ANOVA were used to compare the biofilm formation, planktonic growth, and the gene expression of $C$. albicans strains in the presence or absence of HS. Results with a $p$-value less than 0.05 were considered statistically significant.

Table 1 Primers used for RT-PCR experiments

\begin{tabular}{lll}
\hline Primer & Sequence & Tm ( $^{\circ} \mathbf{C}$ \\
\hline ALS1-F & 5'-CCTATCTGACTAAGACTGCACC-3' & 57.69 \\
ALS1-R & 5'-ACAGTTGGATTGGCAGTGGA-3' & 60.13 \\
ALS3-F & 5'-ACCTGACTAAAACTGCACCAA-3' & 57.71 \\
ALS3-R & 5'-GCAGTGGAACTTGCACAACG-3' & 60.59 \\
HWP1-F & 5'-CTCCAGCCACTGAAACACCA-3' & 60.18 \\
HWP1-R & 5'-GGTGGAATGGAAGCTTCTGGA-3' & 60.00 \\
ECE1-F & 5'-CCCTCAACTTGCTCCTTCACC-3' & 59.96 \\
ECE1-R & 5'-GATCACTTGTGGGATGTTGGTAA-3' & 59.82 \\
BCr1-F & 5'-GCATTGGTAGTGTGGGAAGTTTGAT-3' & 57.64 \\
BCr1-R & 5'-AGAGGCAGAATCACCCACTGTTGTA-3' & 59.96 \\
ACT1-F & 5'-CGTTGTCCAATTACGCTGGT-3' & 60.03 \\
ACT1-R & 5'-TGTTCGAAATCCAAAGCAACG-3' & 58.01 \\
\hline
\end{tabular}




\section{Additional files}

Additional file 1: C. albicans ATCC 90028 was incubated in polypropylene microtiter plates at $37^{\circ} \mathrm{C}$ in the absence or presence of HS (50\%) and the plates were placed on Live Cell Movie Analyzer. The instrument was set to continuous photographing mode with exposure 5\%, brightness 13\%, zoom level 4, interval $1 \mathrm{~min}$, and total time $2 \mathrm{~h}$ (the experimental group was prolonged to $3 \mathrm{~h}$ ). Movie 1 Video of $\mathrm{C}$. albicans biofilm grown in the RPMI 1640 without HS during the first $2 \mathrm{~h}$ (0-120 min). Movie 2 Video of C. albicans biofilm grown in the RPMI 1640 with HS during the first $2 \mathrm{~h}$ (0-120 min). Movie 3 Video of C. albicans biofilm grown in the RPMI 1640 with HS in 120-180 min.

\section{Additional file 2: Light microscopy images of C. albicans} ATCC 90028 biofilms in RPMI and RPMI + HS media. The different panels show photomicrographs taken at various time points during germ tube formulation, as indicated.

\section{Competing interests}

The authors declare that they have no competing interests.

\section{Authors' contributions}

XRD conceived and designed the experiments and carried out most of the data collection and drafted the manuscript. ZHZHL participated in data analysis and interpretation and drafted the manuscript. JRS conceived the study, participated in its design and revised the manuscript. DHY contributed to data analysis. All authors read and approved the final manuscript.

\section{Acknowledgements}

This study was supported in part by the National Natural Science Foundation of China [grant number 30972819]. The funders had no role in study design, data collection and analysis, decision to publish, or preparation of the manuscript.

\section{Author details}

${ }^{1}$ Clinical Laboratory Center, Beijing Friendship Hospital, Capital Medical University, Beijing 100050, China. ${ }^{2}$ The Centre for Laboratory Diagnosis, Beijing Tiantan Hospital, Capital Medical University, Beijing 100050, China.

Received: 12 October 2013 Accepted: 21 March 2014

Published: 28 March 2014

\section{References}

1. Wisplinghoff $H$, Bischoff $T$, Tallent SM, Seifert $H$, Wenzel RP, Edmond MB: Nosocomial bloodstream infections in US hospitals: analysis of 24,179 cases from a prospective nationwide surveillance study. Clin Infect Dis 2004, 39:309-317.

2. Hajjeh RA, Sofair AN, Harrison LH, Lyon GM, Arthington-Skaggs BA, Mirza SA, Phelan M, Morgan J, Lee-Yang W, Ciblak MA, Benjamin LE, Sanza LT, Huie S, Yeo SF, Brandt ME, Warnock DW: Incidence of bloodstream infections due to Candida species and in vitro susceptibilities of isolates collected from 1998 to 2000 in a population-based active surveillance program. J Clin Microbiol 2004, 42:1519-1527.

3. Kumamoto CA: Candida biofilms. Curr Opin Microbiol 2002, 5:608-611.

4. Douglas $\sqcup$ : Candida biofilms and their role in infection. Trends Microbiol 2003, 11:30-36.

5. Kojic EM, Darouiche RO: Candida infections of medical devices. Clin Microbiol Rev 2004, 17:255-267.

6. Ramage G, Saville SP, Thomas DP, López-Ribot JL: Candida biofilms: an update. Eukaryot Cell 2005, 4:633-638.

7. López-Ribot JL: Candida albicans biofilms: more than filamentation. Curr Biol 2005, 15:R453-R455.

8. Li F, Svarovsky MJ, Karlsson AJ, Wagner JP, Marchillo K, Oshel P, Andes D, Palecek SP: Eap1p, an Adhesin That Mediates Candida albicans Biofilm Formation in Vitro and in Vivo. Eukaryot Cell 2007, 6:931-939.

9. Deveau A, Hogan DA: Linking quorum sensing regulation and biofilm formation by Candida albicans. Methods Mol Biol 2011, 692:219-233.

10. Nobile CJ, Fox EP, Nett JE, Sorrells TR, Mitrovich QM, Hernday AD, Tuch BB, Andes DR, Johnson AD: A recently evolved transcriptional network controls biofilm development in Candida albicans. Cell 2012, 148:126-138.
11. Nobile CJ, Mitchell AP: Genetics and genomics of Candida albicans biofilm formation. Cell Microbiol 2006, 8:1382-1391.

12. Nobile CJ, Andes DR, Nett JE, Smith FJ, Yue F, Phan QT, Edwards JE, Filler SG, Mitchell AP: Critical Role of Bcr1-Dependent Adhesins in C. albicans Biofilm Formation In Vitro and In Vivo. PLoS Pathog 2006, 2:636-649.

13. Ganguly S, Mitchell AP: Mucosal biofilms of Candida albicans. Curr Opin Microbiol 2011, 14:380-385.

14. Samaranayake YH, Cheung BP, Yau JY, Yeung SK, Samaranayake LP: Human Serum Promotes Candida albicans Biofilm Growth and Virulence Gene Expression on Silicone Biomaterial. PLoS One 2013, 8:e62902.

15. Abraham NM, Jefferson KK: A low molecular weight component of serum inhibits biofilm formation in Staphylococcus aureus. Microb Pathog 2010, 49:388-391.

16. Hammond A, Dertien J, Colmer-Hamood JA, Griswold JA, Hamood AN: Serum inhibits $P$. aeruginosa biofilm formation on plastic surfaces and intravenous catheters. J Surg Res 2010, 159:735-746.

17. Singh PK, Parsek MR, Greenberg EP, Welsh MJ: A component of innate immunity prevents bacterial biofilm development. Nature 2002, 417:552-555.

18. Cole GT, Halawa AA, Anaissie EJ: The role of the gastrointestinal tract in hematogenous candidiasis: from the laboratory to the bedside. Clin Infect Dis 1996, 22(Suppl 2):73-88

19. Rogers T, Balish E: Experimental Candida albicans infection in conventional mice and germfree rats. Infect Immun 1976, 14:33-38.

20. Calderone RA, Fonzi WA: Virulence factors of Candida albicans. Trends Microbiol 2001, 9:327-335.

21. Biswas S, Van Dijck P, Datta A: Environmental sensing and signal transduction pathways regulating morphopathogenic determinants of Candida albicans. Microbiol Mol Biol Rev 2007, 71:348-376.

22. Huang G: Regulation of phenotypic transitions in the fungal pathogen Candida albicans. Virulence 2012, 3:251-261.

23. Martin R, Albrecht-Eckardt D, Brunke S, Hube B, Hünniger K, Kurzai O: A core filamentation response network in Candida albicans is restricted to eight genes. PLoS One 2013, 8:e58613.

24. Ramage G, VandeWalle K, López-Ribot JL, Wickes BL: The filamentation pathway controlled by the Efg1 regulator protein is required for normal biofilm formation and development in Candida albicans. FEMS Microbiol Lett 2002, 214:95-100.

25. Argimón S, Wishart JA, Leng R, Macaskill S, Mavor A, Alexandris T, Nicholls S, Knight AW, Enjalbert B, Walmsley R, Odds FC, Gow NA, Brown AJ: Developmental regulation of an adhesin gene during cellular morphogenesis in the fungal pathogen Candida albicans. Eukaryot Cell 2007, 6:682-692

26. Rodier MH, Imbert C, Kauffmann-Lacroix C, Daniault G, Jacquemin JL: Immunoglobulins $\mathrm{G}$ could prevent adherence of Candida albicans to polystyrene and extracellular matrix components. J Med Microbio/ 2003, 52(Pt 5):373-377

27. Tsai PW, Yang CY, Chang HT, Lan CY: Human antimicrobial peptide LL-37 inhibits adhesion of Candida albicans by interacting with yeast cell-wall carbohydrates. PLoS One 2011, 6:e17755.

28. Ardehali $R$, Shi L, Janatova J, Mohammad SF, Burns GL: The inhibitory activity of serum to prevent bacterial adhesion is mainly due to apo-transferrin. J Biomed Mater Res A 2003, 66:21-28.

29. Finkel JS, Mitchell AP: Genetic control of Candida albicans biofilm development. Nat Rev Microbiol 2011, 9:109-118.

30. Nobile CJ, Schneider HA, Nett JE, Sheppard DC, Filler SG, Andes DR, Mitchell AP: Complementary adhesin function in C. albicans biofilm formation. Curr Biol 2008, 18:1017-1024

31. Finkel JS, Xu W, Huang D, Hill EM, Desai JV, Woolford CA, Nett JE, Taff H, Norice CT, Andes DR, Lanni F, Mitchell AP: Portrait of Candida albicans Adherence Regulators. PLoS Pathog 2012, 8:e1002525.

32. Nobile CJ, Mitchell AP: Regulation of cell-surface genes and biofilm formation by the C. albicans transcription factor Bcr1p. Curr Biol 2005, 15:1150-1155

33. Hoyer LL: The ALS gene family of Candida albicans. Trends Microbiol 2001, 9:176-180.

34. Sheppard DC, Yeaman MR, Welch WH, Phan QT, Fu Y, Ibrahim AS, Filler SG, Zhang M, Waring AJ, Edwards JE Jr: Functional and structural diversity in the Als protein family of Candida albicans. J Biol Chem 2004, 279:30480-30489. 
35. Zhao X, Oh SH, Yeater KM, Hoyer LL: Analysis of the Candida albicans Als $2 p$ and Als $4 p$ adhesins suggests the potential for compensatory function within the Als family. Microbiology 2005, 151(Pt 5):1619-1630.

36. Bastidas RJ, Heitman J, Cardenas ME: The protein kinase Tor1 regulates adhesin gene expression in Candida albicans. PLoS Pathog 2009, 5:e1000294.

37. Sundstrom P: Adhesion in Candida spp. Cell Microbiol 2002, 4:461-469.

38. Nobile CJ, Nett JE, Andes DR, Mitchell AP: Function of Candida albicans Adhesin Hwp1 in Biofilm Formation. Eukaryot Cell 2006, 5:1604-1610.

39. Ramage G, Vande Walle K, Wickes BL, López-Ribot JL: Standardized method for in vitro antifungal susceptibility testing of Candida albicans biofilms. Antimicrob Agents Chemother 2001, 45:2475-2479.

40. Chandra J, Mukherjee PK, Ghannoum MA: In vitro growth and analysis of Candida biofilms. Nat Protoc 2008, 3:1909-1924.

Cite this article as: Ding et al:. Human serum inhibits adhesion and biofilm formation in Candida albicans. BMC Microbiology 2014 14:80.

\section{Submit your next manuscript to BioMed Central and take full advantage of:}

- Convenient online submission

- Thorough peer review

- No space constraints or color figure charges

- Immediate publication on acceptance

- Inclusion in PubMed, CAS, Scopus and Google Scholar

- Research which is freely available for redistribution 